\title{
On the scaling of activity in tropical forest mammals
}

Bruno Cid ${ }^{1}$, Chris Carbone ${ }^{2}$, Fernando A. S. Fernandez ${ }^{1}$, Patrick A. Jansen ${ }^{3,4}$, J. Marcus Rowcliffe $^{2}$, Timothy O'Brien ${ }^{5}$, Emmanuel Akampurira ${ }^{7}$, Robert Bitariho ${ }^{7}$, Santiago Espinosa $^{6,8}$, Krishna Gajapersad ${ }^{9}$, Thiago M. R. Santos ${ }^{15}$, André L. S. Gonçalves ${ }^{10}$, Margaret F. Kinnaird ${ }^{11}$, Marcela G. M. Lima ${ }^{12}$, Emanuel Martin ${ }^{13}$, Badru Mugerwa ${ }^{7}$, Francesco Rovero $^{14}$, Julia Salvador ${ }^{5,6}$, Fernanda Santos ${ }^{12}$, Wilson R. Spironello ${ }^{10}$, Soraya Wijntuin ${ }^{9}$ and Luiz Gustavo R. Oliveira-Santos ${ }^{15}$

${ }^{1}$ Univ. Federal do Rio de Janeiro, Rio de Janeiro, Brazil

${ }^{2}$ Zoological Society of London, London, England

${ }^{3}$ Jansen, Smithsonian Tropical Res. Inst., Balboa Ancon, Ciudad de Panamá, Panama

${ }^{4}$ Wageningen Univ., Wageningen, the Netherlands

${ }^{5}$ Wildlife Conservation Society, New York, NY, USA

${ }^{6}$ Pontificia Univ. Católica del Ecuador, Vicente Ramón Roca, Quito, Equador

${ }^{7}$ Inst. of Tropical Forest Conservation, Mbarara, Uganda

${ }^{8}$ Univ. Autónoma de San Luis Potosí, San Luis de Potosí, Mexico

${ }^{9}$ Conservation International Suriname, Paramaribo, Suriname

${ }^{10}$ Inst. Nacional de Pesquisas da Amazônia, Manaus, Brazil

${ }^{11}$ World Wide Fund For Nature - International, Gland, Switzerland

${ }^{12}$ Univ. Federal do Pará, Guamá, Belém, Brazil

${ }^{13}$ College of African Wildlife Management, Moshi, Tanzania

${ }^{14}$ MUSE - Museo delle Scienze, Trento, Italy

${ }^{15}$ Univ. Federal do Mato Grosso do Sul, Cidade Universitária - Av. Costa e Silva Pioneiros, Mato Grosso do Sul, Brazil

Corresponding author: Luiz Gustavo R. Oliveira-Santos, Univ. Federal do Mato Grosso do Sul, Cidade Universitária - Av. Costa e Silva - Pioneiros, Mato Grosso do Sul, Brazil. E-mail: gu_tapirus@hotmail.com

Decision date: $31-\mathrm{Dec}-2019$

This article has been accepted for publication and undergone full peer review but has not been through the copyediting, typesetting, pagination and proofreading process, which may lead to differences between this version and the Version of Record. Please cite this article as doi: [10.1111/oik.07022]. 


\section{ABSTRACT}

Activity range - the amount of time spent active per day - is a fundamental aspect contributing to the optimization process by which animals achieve energetic balance. Based on their size and the nature of their diet, theoretical expectations are that larger carnivores need more time active to fulfil their energetic needs than do smaller ones and also more time active than similar-sized non-carnivores. Despite the relationship between daily activity, individual range and energy acquisition, large-scale relationships between activity range and body mass among wild mammals have never been properly addressed. This study aimed to understand the scaling of activity range with body mass, while controlling for phylogeny and diet. We build simple empirical predictions for the scaling of activity range with body mass for mammals of different trophic guilds and used a phylogenetically controlled mixed model to test these predictions using activity records of 249 mammal populations (128 species) in 19 tropical forests (in 15 countries). The empirical predictions showed a steeper scaling of activity range in carnivores (0.21) with higher levels of activity (higher intercept), and near-zero scaling in herbivores (0.04). Empirical data showed that activity ranges scaled positively with body mass for carnivores (0.061), which also had higher intercept value, but not for herbivores, omnivores and insectivores, in general, corresponding with the predictions. Despite the many factors that shape animal activity at local scales, we found a general pattern showing that large carnivores need more time active in a day to meet their energetic demands.

Keywords: activity behavior, body mass, camera traps, diet, energy budget, predation risk 


\section{Introduction}

Activity range - the amount of time, in hours, spent active per day - is a fundamental outcome of the complex physiological and behavioral optimization process by which animals ensure that energy input keeps pace with energy output. In addition to basal metabolism, animals face costs of foraging, acquiring mates and shelter, building reserves for lean times, and escaping predators (Carbone et al. 2007, Halle and Stenseth 2012). Environmental and ecological factors that vary through the day (e.g., luminosity, temperature, predation risk, and competition avoidance) constrain activity to certain times, depending on morpho-physiological limitations (Castillo-Ruiz et al. 2012, Hut et al. 2012). In addition, animals need time to rest in order to recover their cognitive or physical condition (Siegel 2005). Thus, they must optimize their activity range to meet their resource requirements, while dealing with natural daily cycles and saving time for sleep/rest (e.g., Downes 2001, Siegel 2005, Cozzi et al. 2012).

The resource requirements of mammals are related to basal metabolic rate, which scales positively with body mass (Kleiber 1932, Isaac and Carbone 2010), while predation risk decreases with body mass (Sinclair et al. 2003, Hopcraft et al. 2009). Because high predation risk constrains activity while high resource needs increases activity range (e.g., Cozzi et al. 2012, Suselbeek et al. 2014), the question arises whether and how activity range also scales with body mass. Day range (total distance travelled in a day) and home range (area in which animals perform their daily activities) sizes scales positively with body mass and are key metrics to understand the resource requirements of an animal (McNab 1963, Kelt and Van Vuren 2001, Carbone et al. 2005, Tamburello et al. 2015). As activity range is related to space-use metrics (i.e., home range and day range), it is hence, also related to the acquisition of energy. Given that, one might expect activity range to increase with body mass. However, we have a poor understanding of how this relationship actually looks. Previous work developed 
predictions of body mass scaling with day range (Garland 1983, Carbone et al. 2005) and travel speed (Carbone et al. 2007, Rowcliffe et al. 2016). From a simple physical viewpoint, activity range should equal the day range divided by average travel speed. It should thus be possible to infer the scaling of activity range with body mass from these relationships.

Some of the variation in space use across species that is not explained by body mass is associated with different evolutionary histories and ecological traits (e.g., McNab 1963, Kelt and Van Vuren 2001, Price and Hopkins 2015, Tamburello et al. 2015). Diet is the most conspicuous of these, because primary and secondary productivity present different overall yields and accessibility for consumers (Jetz et al. 2004), which in turn influence individual movements (Carbone et al. 2005) and potentially activity range, when exploiting resources at different trophic levels. The nature of the diet aggravates the higher energetic demands of larger carnivores. Predators have considerable energetic constraints related to hunting and handling their prey (Gorman et al. 1998, Carbone et al. 1999) as animal prey can be rare, widely dispersed, unpredictable in time and space and not storable (Jetz et al. 2004, Carbone et al. 2007). Therefore, carnivores have the lowest energy supply rates (supply rate of usable resources available inside the home range), independent of body mass, when compared to other diet categories (Jetz et al. 2004) besides exploring larger areas and traveling greater daily distances (McNab 1963, Kelt and Van Vuren 2001, Carbone et al. 2005, Tamburello et al. 2015). Therefore, larger animals occupy larger areas than small ones, and carnivores occupy larger areas than do similar-sized non-carnivores (Jetz et al. 2004, Tamburello et al. 2015).

To date, few studies have considered interspecific variation in activity range with body mass and other species traits. For example, van Schaik and Griffiths (1996) and Gómez et al. (2005) anecdotally suggested that larger mammal species are 
cathemeral (i.e., active day and night), which implies that they can be active during a larger proportion of the 24-h cycle. Rowcliffe et al. (2014) found that activity range is positively correlated with body mass in tropical forest mammals in Panama. Ramesh et al. (2015) found a negative relationship between body mass and activity concentration (i.e., how concentrated in few hours is the activity of an animal during the day) in Indian mammals, also equating to a positive association between activity range and body mass. However, no study has explored variation in activity range across a diverse range of species, while controlling for phylogeny and diet. This has been, at least in part, due to a lack of consistent data available on a wide range of species. Recent work using camera traps (Oliveira-Santos et al. 2013, Rowcliffe et al. 2014), however, has demonstrated that accurate estimates of activity range can be obtained from photographic records from camera traps. Given the large and rapidly increasing volume of camera-trapping data available globally (Burton et al. 2015), these approaches, consistently applied across a wide range of studies, can provide an important basis for the large-scale study of activity.

Here, we provided simple empirical predictions for the scaling of activity range with body mass for mammals of different trophic guilds. To test these predictions, we estimated the activity range for 249 populations of 128 terrestrial mammal species across 19 tropical forests, and used a phylogenetically controlled mixed model to determine how activity range scales with body mass by diet. As larger animals occupy larger areas than small ones, and carnivores occupy larger areas than do similar-sized non-carnivores (Jetz et al. 2004), we hypothesize that carnivores will present a higher scaling of activity range with body mass and also higher activity ranges for a given mass (higher intercept) when compared to herbivores, omnivores and insectivores.

\section{Material and Methods}




\section{Empirical predictions}

Carbone et al. (2005) found that day range scaled with body mass by a factor 0.44 for carnivores and 0.13 for herbivores. Movement speed was found to scale with body mass by a factor 0.23 for carnivores and 0.09 for herbivores (Rowcliffe et al. 2016). To provide an expectation for the relationship between activity range and body mass, we derived the scaling of activity range from these established scaling relationships. This was based on the notion that the total distance travelled in a day (day range, $R$ ) is the product of travel speed while active $(S)$ and daily time spent active ( $A$; activity range): $R$ $=S A$. Activity range (in $\mathrm{h} / \mathrm{d}$ ) can therefore be derived from day range (in $\mathrm{km} / \mathrm{d}$ ) and speed while active (in $\mathrm{km} / \mathrm{h}$ ) as: $A=R / S$ (activity range = day range/travel speed). Given body mass, $M$, the scaling relationships for day range: $R \propto M^{r}$ (Garland 1983, Carbone et al. 2005); and the scaling relationship for speed: $S \propto M^{S}$ (von Buddenbrock 1934, Schmidt-Nielsen 1984, Rowcliffe et al. 2016), the scaling of activity with body mass is: $A \propto M^{r-s}$.

\section{Empirical data}

We obtained empirical data on activity range from camera-trapping surveys in 19 tropical forests, distributed over four continents. Seventeen sites were part of the Tropical Ecology Assessment and Monitoring Network (see Jansen et al. 2014; data available from TEAM digital repository: http://www.teamnetwork.org), and two additional sites were located in South America (Figure 1). All sites were surveyed by 50 non-baited cameras, spaced $2 \mathrm{~km}$ from each other. The camera grid was set for 30 consecutive days, during dry seasons, totalizing 1,500 camera-days, according to the standardized TEAM protocol (TEAM 2011, Cid et al. 2012).

We trimmed the photographic captures (henceforth "records") in each database to meet the minimum of 1-hr interval between consecutive records of the same species 
at the same camera site to reduce temporal dependence (Gómez et al. 2005). At each site, we only used species that had a minimum of 30 independent records, and excluded Homo sapiens and domesticated animals (as all surveyed sites were inside protected areas, the influence of people and domestic animals on the wildlife activity can be considered negligible). We defined the minimum of 30 records per species after performing analysis of sampling sufficiency through bootstrapping in order to estimate activity ranges (for more details see Appendix S1 in Supporting Information; Figure S1.2. A, B, C, D and E).

We measured the activity range of populations by fitting one-dimensional circular kernel function to the clock time at which animals were recorded (OliveiraSantos et al. 2013). We estimated the activity range as the $95 \%$ isopleth of the circular distribution - the timespan, in hours, during which $95 \%$ of the population activity occurs. We set the smoothing parameter of the kernel function to five to maintain consistency in characterization of activity range among species (Oliveira-Santos et al. 2013). To seek for consistency between the two available metrics associated to activity range, we also estimated the activity range metric proposed by Rowcliffe et al. (2014), which also relies on one-dimensional circular kernel functions, but provide an estimation of the daily proportion of time spent active. We took species body mass and diet (carnivorous, herbivorous, insectivorous or omnivorous) from the PanTHERIA database (Jones et al. 2009).

\section{Potential bias in activity range estimation}

Camera traps can show bias favouring data on larger animals (Burton et al. 2015) because of increased detection range and day range (Rowcliffe et al. 2014, 2016). If there was bias favoring the capture of larger animals in our dataset, it could also bias our results. To check if this was a potential problem in our analysis, we (1) calculated 
the distribution of body size classes among the mammalian species analysed in this study; (2) used a linear model to understand the relationship between body mass and the number of independent records for the 249 populations in our dataset; (3) simulated the sensibility of the activity range estimation to the number of independent records, using five species with different activity patterns as models; and (4) included the number of independent records in the model to understand its influence as a covariate.

The distribution of body size classes (small, medium and large) among the mammalian species showed that we have a balanced representation in our dataset. The linear model showed no relationship between body mass and the number of independent records in a natural logarithm scale $\left(F_{1,247}=0.337 ; \mathrm{r}=0.001 ; \mathrm{p}=0.561\right)$. Even if there was a positive relationship between both variables, the simulations showed that the activity range estimation is robust for sampling sizes above our stablished minimum of 30 independent records. Finally, the inclusion of the number of independent records in the model showed that this covariate had no significant effect (for more details see Appendix S1 in Supporting Information; Figures S1.1 and S1.2. A, B, C, D and E). Based on this analyses and simulations, we conclude that, at least in our case, the camera traps produced reliable and unbiased estimates, allowing cross-species and cross-site analyses.

\section{Analysis}

We used a phylogenetically controlled general linear mixed model (henceforth "GLMM-phy") to determine how activity range (continuous $\log _{\mathrm{e}}$-transformed response variable) scaled with body mass (continuous $\log _{\mathrm{e}}$-transformed fixed predictive variable) by diet class (categorical fixed predictive variable). We included the interaction between body mass and diet, with random intercepts for sites. We built the phylogenetic distance matrix among species based on the supertree of Fritz et al. (2009). In the few 
cases (seven cases) where a species was not already included in the supertree, we coded it as the most related species. We assigned a phylogenetic distance of zero for populations of the same species in different sites. To control for phylogenetic autocorrelation structure in our model, we decomposed the phylogenetic matrix distance into a set of eigenvectors, and included them in the GLMM-phy as fixed variables (Diniz-Filho et al. 2012). To determine the number of axes to be included, we first selected the axes that together explained $95 \%$ of the variation in the phylogenetic distance. Then, we sequentially added axes in the GLMM-phy until the phylogenetic autocorrelation of the model residuals was controlled, verified by the Moran's I index (Diniz-Filho et al. 2012). We estimated the parameters by maximum likelihood and presented in the results as mean values and $95 \%$ confidence intervals (lower limit upper limit). We used R v.3.0.1 (R Development Core Team 2016) for all analyses, with the packages 'activity' (Rowcliffe 2019), 'adephylo' (Jombart et al. 2017), 'circular' (Lund et al. 2017), 'Ime4' (Bates et al. 2018), 'MuMin' (Barton 2018), 'nlme’ (Pinheiro et al. 2018) and 'PVR' (Santos 2018).

\section{Results}

\section{Empirical predictions}

Given that the scaling of activity is determined by the subtraction of the scaling factors of day range and speed (respectively $r$ and $s$ ), as $r-s$, activity range should scale with body mass by a factor 0.04 to 0.21 , with a highest value for carnivores $(0.21)$ and a value near zero for herbivores (0.04). Predicted activity ranges for a given mass were longer for carnivores (i.e., a higher intercept in the scaling relationship) than for herbivores, because carnivores have 2.5 times greater day ranges for a given body mass than herbivores (Carbone et al. 2005). 


\section{Empirical scaling}

We compiled empirical data on activity for 249 populations of 128 species, ranging from four to 22 species in each study site (median $=13$; Figure 1). Of these populations, 99 were herbivores (54 species), 83 omnivores (45 species), 38 insectivores (14 species) and 29 carnivores (15 species; Figure 2). Body mass spanned five orders of magnitude ranging from $0.07 \mathrm{Kg}$ for the Boehm's bush squirrel (Paraxerus boehmi) to $3824 \mathrm{Kg}$ for the African elephant (Loxodonta africana). The first 67 axes explained $95 \%$ of variation in phylogenetic distance. After sequential inclusion, four axes were enough to control phylogenetic autocorrelation of model residuals (Moran's I $\mathrm{p}<0.001$ before inclusion; $\mathrm{p}=0.108$ after inclusion).

The activity range varied two-fold across species, from 11.6 hours for the Water Chevrotain (Hyemoschus aquaticus) in Nouabalé-Ndoki National Park (Democratic Republic of Congo) to 22.7 hours for the Wild Boar (Sus scrofa) in Nam Kading National Protected Area (Laos; Figure 2). As expected from theory, there was a positive scaling relationship between activity range and body mass, which differed among diet categories (Figure 3A; see also Appendix S2 in Supporting Information, Figure S2.1). Carnivore activity range scaled with body mass by a factor $0.061(\mathrm{CI}=0.021-0.101 ; \mathrm{p}$ $=0.003)$. Activity range in the other three diet categories did not scale significantly with body mass, as the $95 \%$ confidence intervals of the slope estimates included zero: Herbivores $(0.030 ; \mathrm{CI}=-0.053-0.112)$, Insectivores $(0.008 ; \mathrm{CI}=-0.092-0.108)$ and Omnivores $(0.027 ; \mathrm{CI}=-0.056-0.110$; Figure $3 \mathrm{~B})$. Also as expected, intercept estimates for each diet group differed significantly (Figure 3C). Our model accounted for $52.4 \%$ of the variation in activity range, where phylogeny (PVR axes) explained $12.8 \%$, body mass $15.9 \%$, diet $23.1 \%$ and interaction between body mass and diet $0.6 \%$

(Table 1). The variance of the random intercepts by site $\left(\sigma^{2}=0.001\right)$ was about ten 
times lower than the residual variance $\left(\sigma^{2}=0.014\right)$, meaning that variation explained by site differences was negligible.

Activity range (sensu Rowcliffe et al. 2014) also scaled with body mass in a similar manner for carnivores $(0.097 ; C I=0.027-0.167 ; p=0.007)$, while there was also no significant relationship between activity range and body mass for herbivores $(0.076 ; \mathrm{CI}=-0.067-0.219)$, insectivores $(-0.017 ; \mathrm{CI}=-0.171-0.137)$ and omnivores $(0.065 ; \mathrm{CI}=-0.079-0.209$; see Appendix S3, Figure S3.1, Table S3.1), despite the fact that the correlation between the activity range metrics was moderate (Pearson's $r=$ 0.59). Thus, the relationship between activity range, body mass and diet was consistent irrespective the chosen metric, evidencing model consistency. The scaling values calculated from camera-trap data fell within the range of scaling values derived from established scaling relationships.

\section{Discussion}

The activity-scaling empirical predictions we proposed proved to be an effective starting point to understand the scaling of activity in mammals as long as it predicted a higher positive scaling between body mass and diet for carnivores $(0.21)$ when compared to herbivores (0.04); and also a longer activity range at a given body mass for carnivores. Investigating our empirical data, we found a higher intercept estimate when compared to herbivores and a activity range that also scaled positively with body mass for carnivores $(0.061)$, which showed a scaling value similar to the one described by Rowcliffe et al. (2014) for a single community of Panamanian terrestrial mammals. On the other hand, herbivores, omnivores and insectivores had no apparent scaling with mass, broadly in line with the empirical predictions (performed only for carnivores and herbivores due to lack of data; Carbone et al. 2005, Rowcliffe et al. 2016). 
Allometric relationships are great for understanding very general patterns (e.g., the mean), but do not capture all of the variation in species, nor do they account for all biological or ecological processes. The differences between the predicted and the empirical scaling can be in part explained by the fact that movement speed and day range scaling come from average measures, assuming that these individual characteristics are constant, when they actually vary greatly, especially speed throughout the day. Still regarding speed, our simple model assumed that it related to body mass in a positive linear way. However, there is evidence that the relationship between both variables is hump-shaped, with a slight decrease towards very large animals (Hirt et al. 2017), which are almost exclusively herbivores in terrestrial ecosystems. Also, species composition in the studies used to build the empirical predictions were not all the same as the ones in this study and vice versa, potentially contributing to the differences found. In addition, empirical field data came from a diverse range of environments (e.g., isolated, patchy and entire forests; Beaudrot et al. 2016) and gathering species of markedly different life histories, such as joining browsers and grazers inside herbivores (although preliminary analysis showed no improvement in model fitting when making this distinction).

Although we only found it for carnivores, in general, the positive relationship of activity range and body mass can be related to sleep or resting because of two main energetic mechanisms. On the one side, smaller mammals, with higher mass-specific metabolic rates (Blackburn and Hawkins 2004), sleep more than larger mammals in order to improve energy conservation (Siegel 2005, Savage and West 2007). On the other side, larger mammals spend a greater proportion of their day active to meet their higher absolute metabolic needs, having less time available to sleep (Elgar et al. 1988, Capellini et al. 2008b, Isaac and Carbone 2010). Because of the inverse relationship between being active and sleeping, our results should be expected to contrast perfectly, 
but in a mirrored way, with the allometric scaling relationship of sleep (i.e. the relationship between hours of sleep per day and body mass). In fact, the sleeping allometric scaling exponent is negative, but somehow disconnected with this expectation because of its higher slope (Siegel 2005, Savage and West 2007). This difference can be attributed to the nature of our activity measure. In this study, being active is the same as being on the move, what is not always true, especially on the left side of the relationship between activity range and body mass, where activity ranges are shorter and there is more time to be resting but not sleeping.

Considering mechanisms that only apply to carnivores, our results support the theory and empirical predictions that large predators need to expend more time active to forage, using their energy to move, find and kill animal prey. With increasing carnivore body mass, activity range increases at a greater rate than travel speed. It is therefore possible that along with the constraint on maximum time available for activity there is an even stronger constraint on the speed at which carnivores can move in forest habitats whilst still remaining effective predators, thus, increasing the need to spend more time active to fulfill their energetic needs. In contrast, it is possible that large carnivores that take large preys respond to the higher energetic costs of hunting and prey handling by resting for long periods to counteract this expenditure. However, this energy-saving mechanism has proved to be a popular misconception, even when regarding lions (Hayward and Hayward 2006). The cases where this may be true are exceptions, especially for the carnivores in this study where only $27 \%$ of the populations belong to species with body mass greater than $15 \mathrm{Kg}$, which are supposed to feed on larger prey (Carbone et al. 1999, 2007). In addition, pack hunting could disrupt the relationship between body mass and activity range because energy expenditure is shared among individuals, however, this is not the behavior of any of the species in this study. 
As predicted by the empirical model, we found a low scaling exponent for activity range with body mass for carnivores. We see two possible explanations for this low scaling. First, activity range by definition is bounded within the $24-\mathrm{h}$ cycle. Given the smallest activity range observed in carnivores (14.1 hours for the 1.8 -Kg species [Fossa fossana]), an increase in body mass could never correspond to a proportional enlargement in activity range. Second, smaller mammals can have several sleeping or resting bouts during the day (polyphasic sleep; Capellini et al. 2008a). Therefore, our population-level approach may overestimate the activity range of individual smaller mammals, if there is lack of synchrony among individual patterns (as also noted by Rowcliffe et al. [2014]). However, empirical field data have suggested that the synchrony of circadian activity among individuals is widespread within mammal populations (e.g., Flowerdew 2000, Martins and Harris 2013, Suselbeek et al. 2014) and examples of asynchronous individuals are due to particular cases such as species with polyphasic sleep and large predators whose foraging cycles are longer than a day (Capellini et al. 2008a, Rowcliffe et al. 2014).

Because of the nature of the feeding type, time constraints might not apply as strongly to other diet categories. While carnivorous populations showed higher overall levels of activity and a significant scaling of activity range with body mass, noncarnivores did not. Herbivores, omnivores and insectivores (especially the ones focusing on social insects; Rodrigues et al. 2008) use resources that are storable, more predictable and more abundant than the resources of carnivores, thus containing more energy per-unit home range area when compared with exclusive meat consumers (Jetz et al. 2004). Larger non-carnivore species do explore larger areas (McNab 1963, Kelt and Van Vuren 2001, Carbone et al. 2005), however, may not need to extend their activity range beyond the moments when they feel secure, relying on the high accessibility of their food resources. In addition, plant food resources are harder to 
digest than animal matter (Chivers and Langer 1994), therefore, herbivore mammals may invest more energy in digesting rather than moving, which explains the lack of a relationship between activity range and body mass. The lack of a relationship in insectivores in this study may be also explained by the fact that most of the populations (13/14 species) belong to two early diverging mammal lineages with low metabolism and the presence of torpor (Didelphimorphia and Xenarthra; McNab 1986, Geiser 1998, Nagy et al. 1999, Nagy 2005). So these animals might achieve energetic balance using different strategies than other species with higher metabolic capacity, such as investing in more hours of sleep (e.g., Vizcaíno and Loughry 2008).

Temporal behavior is a result of many environmental (e.g., temperature, luminosity) and ecological (e.g., predation risk, resource abundance, competition avoidance) variables (reviewed in Bridges and Noss 2011, Castillo-Ruiz et al. 2012, Hut et al. 2012). In addition, human disturbances (such as hunting, urban expansion and our very presence) are driving diurnal animals into nocturnal activity, changing the resource availability for them and the competition patterns among species (Gaynor et al. 2018). Beyond these influences, that play important roles in shaping animal activity at local scales, the positive scaling of activity range with body mass showed a general pattern in which large carnivores spend more time active during the day in order to fulfil their energetic needs. The largest carnivores enhance the amount of energy gained per capture by searching for large prey, i.e., by improving their feeding efficiency (Carbone et al. 1999, 2014). However, there is a point when individual predator intake rate reaches an upper limit in response to increasing prey abundance (Holling 1959, Jeschke et al. 2002). Satiation has emerged as the main explanation for the upper limit to prey consumption in types II and III functional responses of predators; i.e. when, from a number of available prey, predation rate does not increase with increasing prey abundance (Jeschke 2002). Our findings suggest that the exhaustion of time available to search, 
capture and handle animal prey, while dealing with other requirements (i.e., mate search, shelter and avoiding hostile encounters), maybe an alternative explanation to the upper limit in prey consumption. These findings contradict the results achieved by Jeschke (2007), who states that carnivores often become satiated and are released from time constraints to meet their energy needs during the 24-h cycle. However, his study has fewer populations than ours and he merged bird and mammal data in his analysis. Moreover, Jeschke (2007) focus only in feeding requirements, while our analysis is on activity, considering other daily needs as well. Our results suggest that large carnivores face a daily struggle for energy (e.g., Cozzi et al. 2012), what could limit their maximum body mass, being much more affected than non-carnivores from decreases in resource abundance. This could be an important information when planning protected areas for this group, one of the most threatened in the world (Purvis et al. 2000, Cardillo et al. 2005), especially at sites where poaching is silently but inexorably reducing prey availability.

Future research might investigate the effects of prey availability in the spatial versus temporal behavior of large carnivores, especially in tropical regions that are facing extreme mammal population reduction and species loss (Dirzo et al. 2014, Pimm et al. 2014) and where there is deficiency of in situ data in protected areas (Beaudrot et al. 2016). In a general way, we believe that our predictions are relevant beyond forested tropical ecosystems, however with some differences. With increasing body mass, there is also an increased difficulty to move in closed habitats such as forests. Thus, we would expect a shallower slope in the relationship between activity range and body mass for carnivores in open habitats, as long as, in condition of moving faster, large predators would need less time active to fulfil their energetic needs (Osftad et al. 2016). Regarding non-tropical ecosystems, we would also expect the general intercept of the relationship to be higher, because of lower resource density towards colder latitudes. 


\section{Declarations}

Acknowledgements - Most data in this publication came from the Tropical Ecology Assessment and Monitoring (TEAM) Network, a collaboration between Conservation International, the Smithsonian Institution, and the Wildlife Conservation Society, and partially funded by these institutions, the Gordon and Betty Moore Foundation, and other donors. We also thank Bukit Barisan Selatan National Park/Wildlife Conservation Society-Indonesia Program, Estação Científica Ferreira Penna (MPEG/MCTI), Instituto Nacional de Pesquisas da Amazônia and Pontificia Universidad Católica del Ecuador. Finally, we thank Ahimsa Campos-Arceiz, Ben Swanepoel, Christine Fletcher, David Kenfack, Jean Claude Razafimahaimodson, Johanna Hurtado, Kelly Boekee, Lazarus Njoh Agwetang, Cletus Arong, Motale Trevor Nimba, Mambo Peter Ekole, Mireille Hockemba, Ingrid Serrano, Alvaro Enrique, Salomon Yoveni, Nicanor Kapeshi Patricia Alvarez-Loayza, Rodolfo Vasquez, Olga Martha Montiel, Rocío Rojas, Luis Valenzuela and William Marthy and all other people who collected TEAM data.

\section{References}

Barton, K. 2018. MuMIn: multi-model inference. https://cran.r-project.org/web /packages/ MuMIn/MuMIn.pdf.

Bates, D. et al. 2018. Lme4: linear Mixed-Effects Models using 'Eigen' and S4. https://cran.r-project.org/web/packages/lme4/lme4.pdf.

Beaudrot, L. et al. 2016. Standardized assessment of biodiversity trends in tropical forest protected areas: the end is not in sight. - PLOS Biol. 14: e1002357.

Blackburn, T. M. and Hawkins, B. A. 2004. Bergamann's rule and the mammal fauna of northern North America. - Ecography 27: 715-724. 
Bridges, A. S. and Noss, A. J. 2011. Behavior and activity patterns. - In: O’Connell, A. F. et al. (eds.), Camera traps in animal ecology: methods and analyses. Springer, pp. $57-69$.

Burton, A. C. et al. 2015. Wildlife camera trapping: a review and recommendations for linking surveys to ecological processes. - J. Appl. Ecol. 52: 675-685.

Capellini, I. et al. 2008a. Phylogenetic analysis of the ecology and evolution of mammalian sleep. - Evolution 62: 1764-1776.

Capellini, I. et al. 2008b. Energetic constraints, not predation, influence the evolution of sleep patterning in mammals. - Funct. Ecol. 22: 847-853.

Carbone, C. et al. 1999. Energetic constraints on the diet of terrestrial carnivores. Nature 402: 286-288.

Carbone, C. et al. 2005. How far do animals go? Determinants of day range in mammals. - Am. Nat. 165: 290-297.

Carbone, C.et al. 2007. The costs of carnivory. - PLOS Biology 5: 363-368.

Carbone, C. et al. 2014. Geometric factors influencing the diet of vertebrate predators in marine and terrestrial environments. - Ecol. Lett. 17: 1553-1559.

Cardillo, M. et al. 2005. Multiple causes of high extinction risk in large mammal species. - Science 309: 1239-1241.

Castillo-Ruiz, A. et al. 2012. In search of a temporal niche: Social interactions. - In: Kalsbeek A. et al. (eds.), The neurobiology of circadian timing. - Prog. Brain Res. 199: $267-280$.

Chivers, D. J. and Langer, P. 1994. The digestive system in mammals: Food, form and function. -- Cambridge Univ. Press.

Cid, B. et al. 2012. Seasonal habitat use of agoutis (Dasyprocta azarae) is driven by the palm Attalea phalerata in Brazilian Pantanal. - Biotropica 45: 380-385. https://doi.org/10.1111/btp.12012 
Cozzi, G. et al. 2012. Fear of the dark or dinner by moonlight? Reduced temporal partitioning among Africa's large carnivores. - Ecology 93: 2590-2599.

Diniz-Filho, J. A. F. et al. 2012. On the selection of phylogenetic eigenvectors for ecological analyses. - Ecography 35: 239-249.

Dirzo, R. et al. 2014. Defaunation in the Anthropocene. - Science 345: 401-406.

Downes, S. 2001. Trading heat and food for safety: Costs of predator avoidance in a lizard. - Ecology 82: 2870-2881.

Elgar, M. A. et al. 1988. Sleep in mammals. - Anim. Behav. 36: 1407-1419.

Flowerdew, J. R. 2000. Woodmice - Small granivores/insectivores with seasonally variable patterns. - In: Halle, S. and Stenseth, S. (eds.), Activity patterns in small mammals: an ecological approach. Springer, pp. 177-190.

Fritz, S. A. et al. 2009. Geographical variation in predictors of mammalian extinction risk: big is bad, but only in the tropics. - Ecol. Lett. 12: 538-549.

Garland, T. 1983. Scaling the ecological cost of transport to body mass in terrestrial mammals. - Am. Nat. 121: 571-587.

Gaynor, K. M. et al. 2018. The influence of human disturbance on wildlife nocturnality. - Science 360: 1232-1235.

Geiser, F. 1998. Evolution of daily torpor and hibernation in birds and mammals: Importance of body size. - Clin. Exp. Pharmacol. Physiol. 25: 736-740.

Gómez, H. et al. 2005. Dry season activity periods of some Amazonian mammals. Stud. Neotrop. Fauna E. 40: 91-95.

Gorman, M. L. et al. 1998. High hunting costs make African wild dogs vulnerable to kleptoparasitism by hyaenas. - Nature 391: 479-481.

Halle, S. and Stenseth, N. C. 2012. Activity patterns in small mammals: An ecological approach. -- Springer. 
Hayward, M. W. and Hayward, G. J. 2006. Activity patterns of reintroduced lion Panthera leo and spotted hyaena Crocuta crocuta in the Addo Elephant National Park, South Africa. - Afr. J. Ecol. 45: 135-141.

Hirt, M. R. et al. 2017. A general scaling law reveals why the largest animals are not the fastest. - Nat. Ecol. Evol. 1: 1116.

Holling, C. S. 1959. The components of predation as revealed by a study of smallmammal predation of the European pine sawfly. - Can. Entomol. 91: 293-320.

Hopcraft, J. G. C. et al. 2009. Herbivores, resources and risks: Alternating regulation along primary environmental gradients in savannas. - Trends. Ecol. Evol. 25: 119128.

Hut, R. A. et al. 2012. In search of a temporal niche: Environmental factors. - In: Kalsbeek A. et al. (eds.), The neurobiology of circadian timing. - Prog. Brain Res. 199: 281-304.

Isaac, N. J. B. and Carbone, C. 2010. Why are metabolic scaling exponents so controversial? Quantifying variance and testing hypotheses. - Ecol. Lett. 13: 728735.

Jansen, P. A. et al. 2014. TEAM: a standardised camera-trap survey to monitor terrestrial vertebrate communities in tropical forests. - In: Fleming, P. et al. (eds.), Camera trapping: wildlife research and management. CSIRO Publishing, pp. 263270.

Jeschke, J. M. et al. 2002. Predator functional responses: discriminating between handling and digesting prey. - Ecol. Monogr. 72: 95-112.

Jeschke, J. M. 2007. When carnivores are full and lazy. - Oecologia 152: 357-364.

Jetz, W. et al. 2004. The scaling of animal space use. - Science 306: 266-268. 
Jombart, T. et al. 2017. Adephylo: exploratory analyses for the phylogenetic comparative method. https://cran.rproject.org/web/packages/adephylo/adephylo.pdf.

Jones, K. E. et al. 2009. PanTHERIA: a species-level database of life history, ecology, and geography of extant and recently extinct mammals. - Ecology 90: 2648-2648.

Kelt, D. A. and Van Vuren, D. H. 2001. The ecology and macroecology of mammalian home range area. - Am. Nat. 157: 637-645.

Kleiber, M. 1932. Body size and metabolism. - Hilgardia 6: 315-353.

Lund, U. et al. 2017. Circular: circular statistics. https://cran.rproject.org/web/packages/ circular/circular.pdf

Martins, Q. and Harris, S. 2013. Movement, activity and hunting behaviour of leopards in the Cederberg mountains, South Africa. - Afr. J. Ecol. 51: 571-579.

McNab, B. K. 1963. Bioenergetics and the determination of home range size. - Am. Nat. 97:

McNab, B. K. 1986. The influence of food habits on the energetics of eutherian mammals. - Ecol. Monogr. 56: 1-19.

Nagy, K. A. 2005. Field metabolic rate and body size. - J. Exp. Biol. 208: 1621-1625.

Nagy K. A. et al. 1999. Energetics of free-ranging mammals, reptiles, and birds. Annu. Rev. Nutr. 19: 247-277.

Ofstad, E. G. et al. 2016. Home ranges, habitat and body mass: simple correlates of home range size in ungulates. Proc. R. Soc. Lond. B. 283: 20161234.

Oliveira-Santos, L. G. R. et al. 2013. Using conditional circular kernel density functions to test hypotheses on animal circadian activity. - Anim. Behav. 85: 269280.

Pimm, S. L. et al. 2014. The biodiversity of species and their rates of extinction, distribution, and protection. - Science 344: 1246752. 
Pinheiro, J. et al. 2018. Nlme: linear and nonlinear mixed effects models. https://cran.rproject.org/web/packages/nlme/nlme.pdf.

Price, S. A. and Hopkins, S. S. B. 2015. The macroevolutionary relationship between diet and body mass across mammals. - Biol. J. Linn. Soc. 115: 173-184.

Purvis, A. et al. 2000. Predicting extinction risk in declining species. - Proc. R. Soc. Lond. B. 267: 1947-1952.

R Development Core Team. 2016. R: A language and environment for statistical computing. R Foundation for Statistical Computing, Vienna, Austria.

Ramesh, T. et al. 2015. Role of body size in activity budgets of mammals in the Western Ghats of India. - J. Trop. Ecol. 31: 315-323.

Rodrigues, F. H. G. et al. 2008. Anteater behavior and ecology. - In: Vizcaíno, S. F. and Loughry, W. J. (eds.), The Biology of the Xenarthra. University press of Florida, pp. 257-268.

Rowcliffe, M. J. 2019. Activity: animal activity statistics. https://cran.rproject.org/web/ packages/activity/activity.pdf.

Rowcliffe, M. J. et al. 2014. Quantifying levels of animal activity using camera trap data. - Methods Ecol. Evol. 5: 1170-1179.

Rowcliffe, M. J. et al. 2016. Wildlife speed cameras: Measuring animal travel speed and day range using camera traps. - Remote Sens. Ecol. Conserv. 2: 84-94.

Santos, T. 2018. PVR: phylogenetic eigenvectors regression and phylogenetic signalrepresentation curve. https://cran.r-project.org/web/packages/PVR/PVR.pdf.

Savage, V. M. and West G. B. 2007. A quantitative, theoretical framework for understanding mammalian sleep. - PNAS 104: 1051-1056.

Schmidt-Nielsen, K. 1984. Scaling: Why is animal size so important? -- Cambridge Univ. Press. 
Siegel, J. M. 2005. Clues to the functions of mammalian sleep. - Nature 437: 12641271.

Sinclair, A. R. E. et al. 2003. Patterns of predation in a diverse predator-prey system. Nature 425: 288-290.

Suselbeek, L. et al. 2014. Food acquisition and predator avoidance in a Neotropical rodent. - Anim. Behav. 88: 41-48.

Tamburello, N. et al. 2015. Energy and the scaling of animal space-use. - Am. Nat. 186: 196-211.

TEAM Network. 2011. Terrestrial Vertebrate Monitoring Protocol (http://www.teamnetwork.org/protocols/bio/terrestrial-vertebrate). Last accessed 09/06/2016.

van Schaik, C. P. and Griffiths, M. 1996. Activity periods of Indonesian rain forest mammals. - Biotropica 28: 105-112.

Vizcaíno, S. F. and Loughry, W. J. 2008. The biology of Xenarthra. -- University Press of Florida.

von Buddenbrock W. 1934. Über die kinetische und statische Leistung großer und kleiner Tiere und ihre Bedeutung für den Gesamtstoffwechsel. Naturwissenschaften 22: 675-680. 


\section{Figure Legends}

Figure 1. Location of the 19 study sites. The size of the dots reflects the number of mammal populations sampled. The dashed lines delimit the tropics (defined as between 30 degrees north and south of the equator). Africa: BIF = Bwindi Impenetrable National Park (Uganda), KRP = Korup National Park (Cameroon), NNN = Nouabalé-Ndoki National Park (Democratic Republic of Congo), RNF = Ranomafana National Park (Madagascar), UDZ = Udzungwa Mountains (Tanzania), VMS = Virunga Massif (Republic of Congo); Asia: BBS = Bukit Barisan (Indonesia), NAK = Nam Kading National Protected Area (Laos), PSH = Pasoh Forest Reserve (Malaysia); Central America: $\mathrm{BCI}=$ Barro Colorado Nature Monument and Soberanía National Park (Panama), VBA = Volcán Barva (Costa Rica); South America: ATF = Santa Catarina Atlantic Forest (Brazil), CAX = Caxiuanã National Forest (Brazil), CCS = Cocha

Cashu-Manu National Park (Peru), CSN = Central Suriname Nature Reserve (Suriname), MAN = Manaus $($ Brazil $)$, PAN $=$ Pantanal $($ Brazil $)$, YAN $=$ YanachagaChemillén National Park (Peru), YAS = Yasuni National Park (Ecuador).



'This article is protected by copyright. All rights reserved.' 
Figure 2. Phylogeny of the 128 tropical mammal species in this study. Names are coloured by diet: carnivores, red; herbivores, green; insectivores, grey; and omnivores, black. Dot colour reflects activity range (mean by species), ranging from short (white) to long (red).

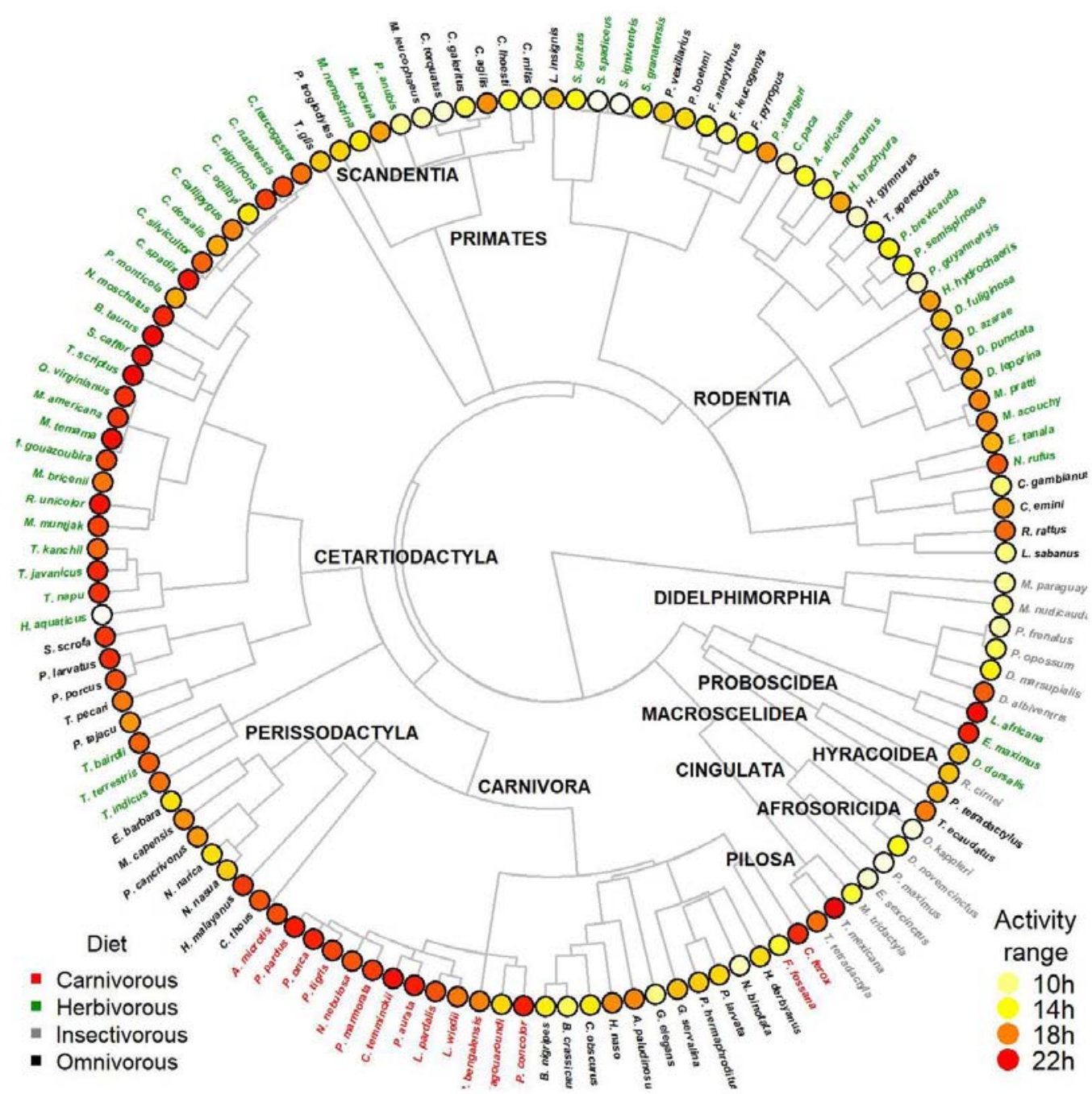

'This article is protected by copyright. All rights reserved.' 
Figure 3. Scaling of activity range with body mass in 249 populations of terrestrial mammals in the tropics. (A) Overall log-log relationship between activity range and body mass. Dashed lines are GLMM fits to the data. Both axes are in natural log scale but real values were printed. (B) Slope estimates. Dots indicate the estimated values and lines the 95\% confidence intervals. (C) Intercept estimates. Dots indicate the estimated values and lines the $95 \%$ confidence intervals. The dashed black line marks the zero. Colour is a guide to diet: carnivores, red; herbivores, green; insectivores, grey; and omnivores, black.
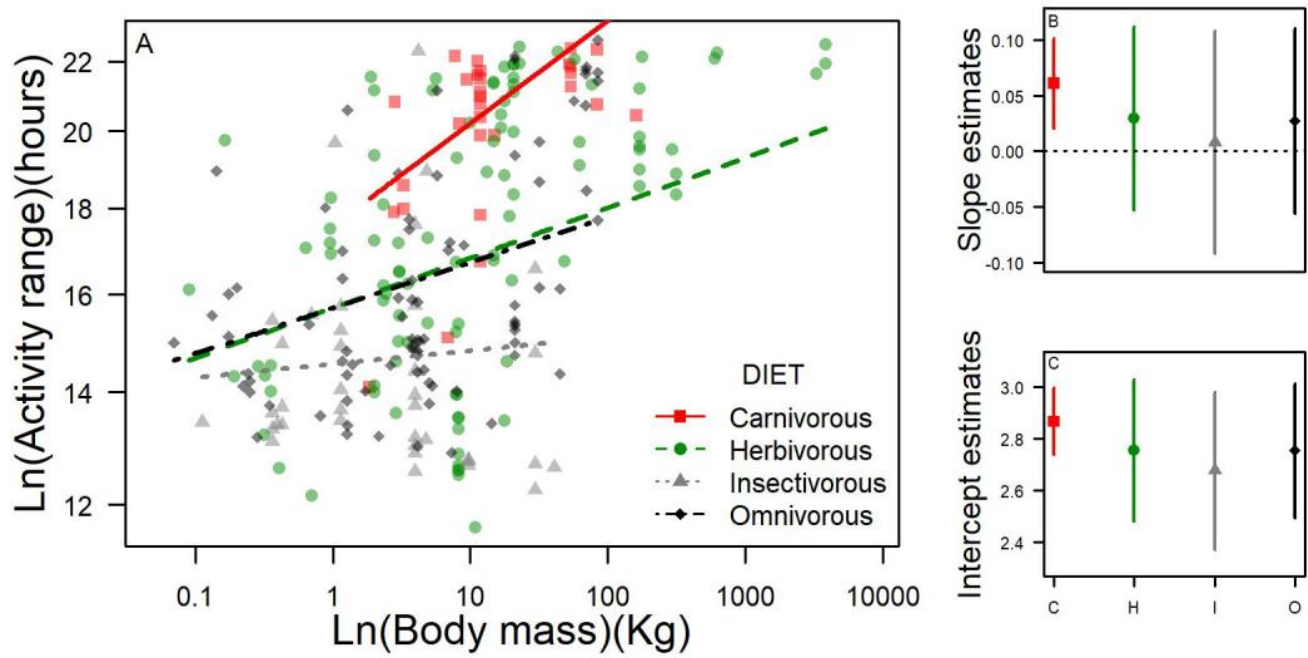

'This article is protected by copyright. All rights reserved.' 


\section{Table Legend}

Table 1. Model (GLMM-phy) estimates. Estimate = mean estimates. Lower and upper $=$ lower and upper limits of the $95 \%$ confidence intervals. $\%$ explained variance $=$ activity range variance explained by each component (phylogeny $[\mathrm{C} 1+\mathrm{C} 2+\mathrm{C} 3+\mathrm{C} 4]$ and ecological variables [body mass, diet and interaction body mass:diet]).

\begin{tabular}{lcccc}
\hline \multicolumn{1}{c}{ Variable } & Estimate & Lower & Upper & \% explained variance \\
\hline Intercept & 2.866 & 2.737 & 2.995 & - \\
Log(mass) & 0.061 & 0.020 & 0.101 & 15.9 \\
Diet herbivorous & -0.111 & -0.257 & 0.033 & 23.1 \\
Diet insectivorous & -0.188 & -0.363 & -0.014 & \\
Diet omnivorous & -0.112 & -0.241 & 0.017 & 12.8 \\
C1 & 0.608 & 0.357 & 0.860 & \\
C2 & 0.574 & 0.265 & 0.883 & \\
C3 & 0.104 & -0.245 & 0.454 & \\
C4 & -0.233 & -0.462 & -0.004 & \\
Diet herbivorous:log(mass) & -0.031 & -0.073 & 0.010 & \\
Diet insectivorous:log(mass) & -0.053 & -0.112 & 0.006 & \\
Diet omnivorous:log(mass) & -0.034 & -0.077 & 0.009 & \\
\hline
\end{tabular}

